Ana Leticia Oliveira do Amaral, Berenice Santos Gonçalves *

\title{
Ensino da fotografia e as Tecnologias Digitais de Informação e Comunicação: \\ um estudo com discentes de uma graduação de Design
}

Ana Letícia Oliveira do Amaral possui graduação em Desenho Industrial - Habilitação em Programação Visual pela Universidade Federal de Santa Maria (UFSM), especialização em Fotografia pela Universidade de Araraquara (UNIARA) e mestrado em Design, linha de pesquisa Mídia e Tecnologia, pela Universidade Federal de Santa Catarina (UFSC). Aluna de doutorado na mesma instituição, na linha de Mídia e Tecnologia. <amaral.analeticia@gmail.com>

ORCID: 0000-0002-5270-9105
Resumo Apesar da imagem fotográfica ter sido trivializada na atualidade, ela tem uma utilização fundamental e extensiva no estudo de diversas áreas do conhecimento. Diante disso, este estudo busca identificar as expectativas de discentes de um curso de Design quanto à disciplina de fotografia e quanto ao conhecimento prévio sobre tecnologias digitais que apresentam potencial para apoiar o ensino dessa disciplina. Dentre os resultados fica evidente que a relação dos alunos com a fotografia é basicamente construída pela utilização da câmera de seus smartphones para fotografar. Além disso, foi possível perceber o interesse dos alunos em compartilhar e trocar informações com os colegas sobre as atividades da disciplina e sobre fotografia, em um ambiente digital que não dependesse somente dos encontros presenciais.

Palavras chave Design, Ensino da fotografia, Tecnologias Digitais de Informação e Comunicação, Estudo prospectivo. 
Berenice Santos Gonçalves possui Doutorado em Engenharia de Produção pela Universidade Federal de Santa Catarina, mestrado em Artes Visuais pela Universidade Federal do Rio Grande do Sul e graduação em Artes Visuais

- Bacharelado e Licenciatura pela Universidade Federal do Rio Grande do Sul. Atualmente exerce a função de professora adjunta na Universidade Federal de Santa Catarina onde ministra disciplinas nas áreas de Teoria da Cor e Ergonomia e usabilidade para o curso de Graduação em Design. Atua nos programas de Mestrado e Doutorado em Design. Desenvolve pesquisas nas linhas de Mídia e Tecnologia. <berenice@cce.ufsc.br > ORCID: 0000-0002-0740-4281

\section{The photographic education and the Digital ICT: a study with students of a Design graduation}

Abstract Although the photographic image has been trivialized today, it has a fundamental and extensive use in the study of various areas of knowledge, has a close relationship with the activities of Design and is primordial to contemporary cultural production. Thus, this study seeks to identify the expectations of students of a Design course regarding the discipline of photography and previous knowledge about digital technologies that have the potential to support the teaching of this discipline. Among the results, it is evident that the students' relationship with photography is basically built by using the camera of their smartphones to photograph. In addition, it was possible to perceive the students' interest in sharing and exchanging information with colleagues about the discipline's activities and photography, in a digital environment that did not depend only on face-to-face meetings.

Keywords Design, Photography education, Digital Information and Communication Technologies, Prospective study.

\section{Enseñanza de fotografía y Tecnologías Digitales de Información y Comunicación: un estudio con estudiantes de una graduación de Diseño}

Resumen Aunque la imagen fotográfica se ha trivializado hoy, tiene un uso fundamental y extenso en el estudio de varias áreas del conocimiento. Por lo tanto, este estudio busca identificar las expectativas de los estudiantes de un curso de Diseño en la disciplina de la fotografía y en términos de conocimiento previo sobre las tecnologías digitales que tienen el potencial de apoyar la enseñanza de esta disciplina. Entre los resultados, es evidente que la relación de los estudiantes con la fotografía se construye básicamente usando la cámara de sus teléfonos inteligentes para fotografiar. Además, fue posible ver el interés de los estudiantes en compartir e intercambiar información con colegas sobre las actividades de la disciplina y sobre la fotografía, en un entorno digital que no dependía solo de reuniones cara a cara.

Palabras clave Diseño, Enseñanza de fotografía, Tecnologías Digitales de Información y Comunicación, Estudio prospectivo. 


\section{Introdução}

A imagem fotográfica possui uma presença ubíqua ${ }^{1}$ na sociedade atual, na qual diversos aparatos capturam e compartilham milhões de imagens a todo momento no mundo (HAND, 2012; SANTAELLA, 2014; MANOVICH, 2017). As funcionalidades dos equipamentos tecnológicos se unem para potencializar a mobilidade e a interatividade dos conteúdos, mudando as relações sociais, tecnológicas, econômicas e industriais. Entretanto, apesar da imagem fotográfica ter sido trivializada na atualidade (SANTAELLA, 2014), ela tem uma utilização fundamental e extensiva no estudo de diversas áreas do conhecimento (RUBINSTEIN, 2009), possui uma estreita relação com as atividades do Design e constitui-se primordial à produção cultural contemporânea.

Smartphones, tablets, câmeras digitais e, até mesmo, acessórios como smartwatches ${ }^{2}$ e óculos ${ }^{3}$ capturam e compartilham imagens. De acordo com Manovich, (2017), em setembro de 2015, o aplicativo Instagram atingiu 400 milhões de usuários e 80 milhões de imagens compartilhadas. Em junho de 2018, conforme o site do próprio aplicativo, atingiu a marca de 1 bilhão ${ }^{4}$ de usuários ativos e cerca de 95 milhões de fotos enviadas para a plataforma todos os dias. Frente a esse significativo crescimento, percebe-se que o aumento da complexidade do aparato tecnológico e a simplificação dos procedimentos fotográficos oportunizados pelas tecnologias digitais, proporcionaram a um maior número de pessoas se expressarem por meio da imagem fotográfica (SANTAELLA, 2014; SILVA, 2016).

Assim, a partir do contexto exposto justifica-se esta pesquisa pois, apesar da expressiva participação da fotografia no cotidiano das pessoas, o número de investigações encontradas em revistas científicas acerca da fotografia, principalmente sobre suas formas de ensino ainda são ínfimas (MARZAL; SOLER, 2011). Cabe ressaltar que as mudanças decorrentes das inovações tecnológicas têm influenciado os modos de aquisição do conhecimento no que se refere à formação de profissionais, principalmente designers, que utilizam a fotografia como um recurso constante. Nesse sentido, os "novos fluxos midiáticos estão impondo mudanças no exercício do ensino, da produção e do consumo de imagens, além de colocarem a prova às teorias elaboradas até agora sobre a imagem fotográfica e suas práticas" (SOBRAL, 2011, p. 137). Além disso, os modelos vigentes de educação estão temporal e espacialmente ultrapassados (MARTÍN-BARBERO, 2014), necessitando assim, que os processos de formação sejam revistos, dado que as tecnologias digitais da informação e da comunicação atravessam todas as atividades ligadas à educação (WAUTERS, 2013).

Nessa perspectiva, demarca-se que a cooperação entre métodos e técnicas presenciais e virtuais no ensino podem auxiliar no acompanhamento do desenvolvimento da aprendizagem, incentivar práticas colaborativas, motivar e envolver os alunos (TORI, 2010). Sobral (2011) defende que o uso de qualquer ferramenta tecnológica, desde que objetive o desenvol- 
vimento ético, criativo e expressivo dos alunos e que esteja inserida em um projeto pedagógico consistente, deve ser utilizada como uma nova estratégia para o ensino e aprendizagem.

Assim, frente a essa problemática, este estudo buscou identificar as expectativas dos alunos de um curso de Design quanto à disciplina de fotografia e quanto ao conhecimento prévio sobre tecnologias digitais que apresentam potencial para apoiar o ensino da fotografia.

Para tanto, a primeira parte deste artigo resgata conceitos sobre o ensino da fotografia frente às tecnologias. Na segunda parte, realizou-se um estudo prospectivo onde foram consultados discentes de uma graduação em Design, devidamente matriculados na disciplina de fotografia, por meio da técnica de Grupo Focal e em seguida, os resultados e discussões são explicitados.

\section{Ensino da fotografia e Tecnologia}

As tecnologias sempre determinaram, em certa medida, aspectos que circundam a valoração da imagem. De acordo com Silva (2016), nos anos iniciais da introdução da imagem digital, os discursos em defesa da película evidenciavam que a ideia de "boa fotografia" estava estreitamente relacionada com o domínio tecnológico. Contudo, para Rivera (2012) é preciso entender que a imagem fotográfica é uma representação pessoal da realidade, a câmera fotográfica é um instrumento e o fotógrafo é que define o olhar, toma decisões e cria a representação. Portanto, aprender fotografia envolve tornar o olhar sensível às relações visuais, sensível às qualidades $\mathrm{e}$ ambientes da luz e ao reconhecimento de assuntos e momentos representativos. Dessa forma, dominar a tecnologia fotográfica vigente não é garantia de bons resultados, é necessário ampliar o repertório de conhecimento das pessoas sobre a fotografia.

De acordo com Abrahmov e Ronen (2008), o objetivo do ensino de fotografia, deve ser o desenvolvimento de habilidades tanto de "leitura" quanto de "escrita" de imagens. Para os autores, explorar o significado de uma fotografia, deve ser mais semelhante com a leitura de uma frase complexa do que com a leitura de uma única palavra. Marzal e Soler (2011), por meio de um estudo sobre os hábitos de consumo e usos da fotografia na era digital entre estudantes de comunicação, concluíram que, por mais conscientes que os estudantes sejam sobre a importância do estudo da fotografia para o seu futuro profissional, existe pouco interesse em aprofundar os conhecimentos sobre esse campo. Além disso, o estudo também apontou que esses estudantes possuem pouco conhecimento sobre a cultura visual. Por mais que a pesquisa já tenha alguns anos, essa afirmação pode ser resultante das facilidades técnicas que as tecnologias digitais trouxeram, e configuram, por sua vez, o importante desafio de como motivar o estudante a buscar e aprofundar os conhecimentos sobre fotografia, utilizando a tecnologia como instrumento de aprendizado e não apenas como um automatizador de processos. 
Para Nieberding (2011), antes da popularização da fotografia digital, os alunos memorizavam configurações de $\mathrm{f} /$ stops e velocidades do obturador, aprendiam as regras de composição, processamento de filme que dominavam o mercado e amplificadores usados para fazer impressões tecnicamente excelentes. $O$ objetivo do ensino nessa área estava ligado ao domínio da arte, da técnica e da tecnologia de fazer fotografias. Atualmente, a educação fotográfica parece possuir como objetivo educar a respeito dos usos do meio, fornecendo uma estrutura crítica para a interpretação de imagens, promover a alfabetização visual e o letramento imagético ${ }^{5}$.

Diante dessas afirmações, entende-se que o modo de ensino da fotografia requer uma inovação constante para manter a relevância frente à cultura contemporânea, visto que, dificilmente, métodos convencionais de ensino conseguem envolver as gerações que já cresceram em uma era digital, na qual a autoaprendizagem e a exploração ativa da informação são tarefas diárias (ROBBINS, 2000; FAKRI; YUSOFF; SAID, 2015; ZHANG et al, 2013). Robbie e Zeeng (2008) apontam, em seu estudo, que para satisfazer as expectativas de ensino e aprendizagem na educação superior do século $\mathrm{XXI}$, as mudanças devem enfatizar as boas características do ensino, a saber, conhecimento, organização, comunicação, entusiasmo, flexibilidade, empatia e respeito, assim como, as qualidades da prática de ensino, ou seja, a reflexão, a criatividade e a tomada de riscos.

Além disso, a incorporação de tecnologias digitais no ensino é fundamental para democratizar o acesso a uma educação superior de qualidade e equidade, ampliar a interiorização e melhorar os processos de ensino e aprendizagem. O relatório Diretrizes de Política Pública para o Ensino Superior Brasileiro, publicado em 2017, afirma que a nova política pública para o ensino superior deve prever que as instituições possam utilizar as possibilidades do ensino digital, com liberdade para inovar e introduzir adaptações permanentes às mudanças registradas nos ambientes tecnológicos e sociais, facilitando um maior acesso ao conhecimento (SEMESP, 2017).

\section{Metodologia}

A fim de identificar as expectativas dos alunos quanto à disciplina de fotografia e quanto ao conhecimento prévio sobre tecnologias digitais que apresentam potencial para apoiar o ensino dessa disciplina, realizou-se um estudo prospectivo com os estudantes, regularmente matriculados na disciplina de fotografia em uma graduação de Design, no sul do país.

Para tanto, optou-se pelo uso da técnica de Grupo Focal. Essa técnica baseia-se em uma entrevista em grupo (normalmente de 3 a 10 participantes), acerca de um tema específico, conduzida por um moderador que apoia a discussão em uma lista de perguntas (ROGERS; SHARP; PREECE, 2013). Quando devidamente orientados os participantes, ao se aceitarem mutuamente como colegas, em um ambiente onde o medo de ser julgado é 
diminuído, são mais propensos a compartilhar experiências, histórias, memórias, percepções, desejos e necessidades (MARTIN; HANINGTON, 2012). Dessa maneira, a pesquisa foi dividida nas seguintes etapas: (I) elaboração do roteiro do grupo focal, (II) agendamento com os professores, (III) convite de participação aos alunos, (IV) realização dos grupos focais, (V) tratamento e análise dos dados e resultados e discussões.

Fig 1. Etapas do

desenvolvimento da pesquisa

Fonte: Das autoras, 2019

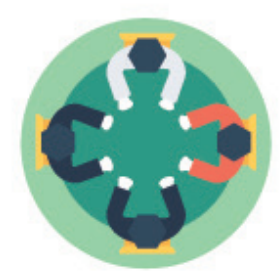

GRUPO FOCAL COM OS ALUNOS
Elaboração do roteiro do grupo focal

Agendamento com os professores

$\checkmark$ Convite de participação aos alunos

$\checkmark$ Realização dos grupos focais

Tratamento e análise dos dados

Resultados e discussões

Assim, a partir do aporte teórico e dos resultados de uma Revisão Sistemática de Literatura, (AMARAL; GONÇALVES; GITIRANA, 2019), foi elaborado um roteiro semiestruturado composto por sete (7) perguntas que apoiaram a discussão. Também foi elaborado um questionário com cinco (5) perguntas, duas abertas e três fechadas, para a caracterização do perfil dos participantes. Além disso, buscou-se um aplicativo de gravação de áudio para registrar os encontros.

Para o agendamento, foi solicitado a dois professores ministrantes da disciplina de fotografia digital, em uma graduação de Design, a possibilidade de efetuar os grupos focais durante a primeira ou segunda aula do semestre letivo 2018-2. Nesse contato, foi explicitado o objetivo do grupo focal e reservadas duas manhãs e uma tarde do mês de agosto de 2018 para a realização dos encontros.

A primeira parte do encontro foi composta pela apresentação dos objetivos da pesquisa e pelo convite aos alunos para participar da discussão. Na sequência, a realização dos encontros se deu nos dias 10, 21 e 22 de agosto de 2018, contando com 36 estudantes.

Cabe ressaltar, que para assegurar a confiabilidade e responsabilidade do projeto, os documentos referentes à pesquisa foram elaborados e submetidos ao Comitê de Ética da Universidade Federal de Santa Catarina, por meio da Plataforma Brasil. Após avaliação do comitê, a pesquisa foi aprovada de acordo com o parecer consubstanciado número 2.766.096.

Para o tratamento dos dados, foi utilizada a abordagem de análise do conteúdo proposta por Bardin (2016). Esta técnica é organizada em três fases: 1) pré-análise, 2) exploração do material e 3) tratamento dos resulta- 
dos, inferência e interpretação, apresentados na figura 2, a seguir. A análise de conteúdo é uma técnica de análise das comunicações. Na análise do material, busca-se classificá-los em temas ou categorias que auxiliam na compreensão do que está por trás dos discursos (SILVA; FOSSÁ, 2015).

A primeira etapa, pré-análise, é a fase de organização, tendo como objetivo principal tornar operacionais e sistematizar as ideias iniciais colocadas pelo referencial teórico, assim como, estabelecer indicadores para a interpretação das informações coletadas. A fase compreende a leitura geral do material escolhido para a análise - no caso deste estudo, são os áudios e anotações dos grupos focais e o questionário de perfil dos alunos. Ou seja, nessa etapa, organiza-se o material a ser investigado. Essa sistematização serve para que o pesquisador possa conduzir as operações de análise. Esta etapa englobou as seguintes subetapas: a) leitura flutuante, b) preparação do material, c) formulação das hipóteses e objetivos, d) elaboração de indicadores.

A exploração do material constitui a segunda etapa, consistindo na construção das operações de codificação, considerando-se os recortes dos textos em unidades de registro, a definição das regras de contagem e a classificação e agregação das informações em categorias. Por fim, a terceira etapa compreende o tratamento dos resultados obtidos e interpretação, ou seja, os resultados brutos são tratados de maneira a serem significativos e válidos (SILVA; FOSSÁ, 2015; BARDIN, 2016).

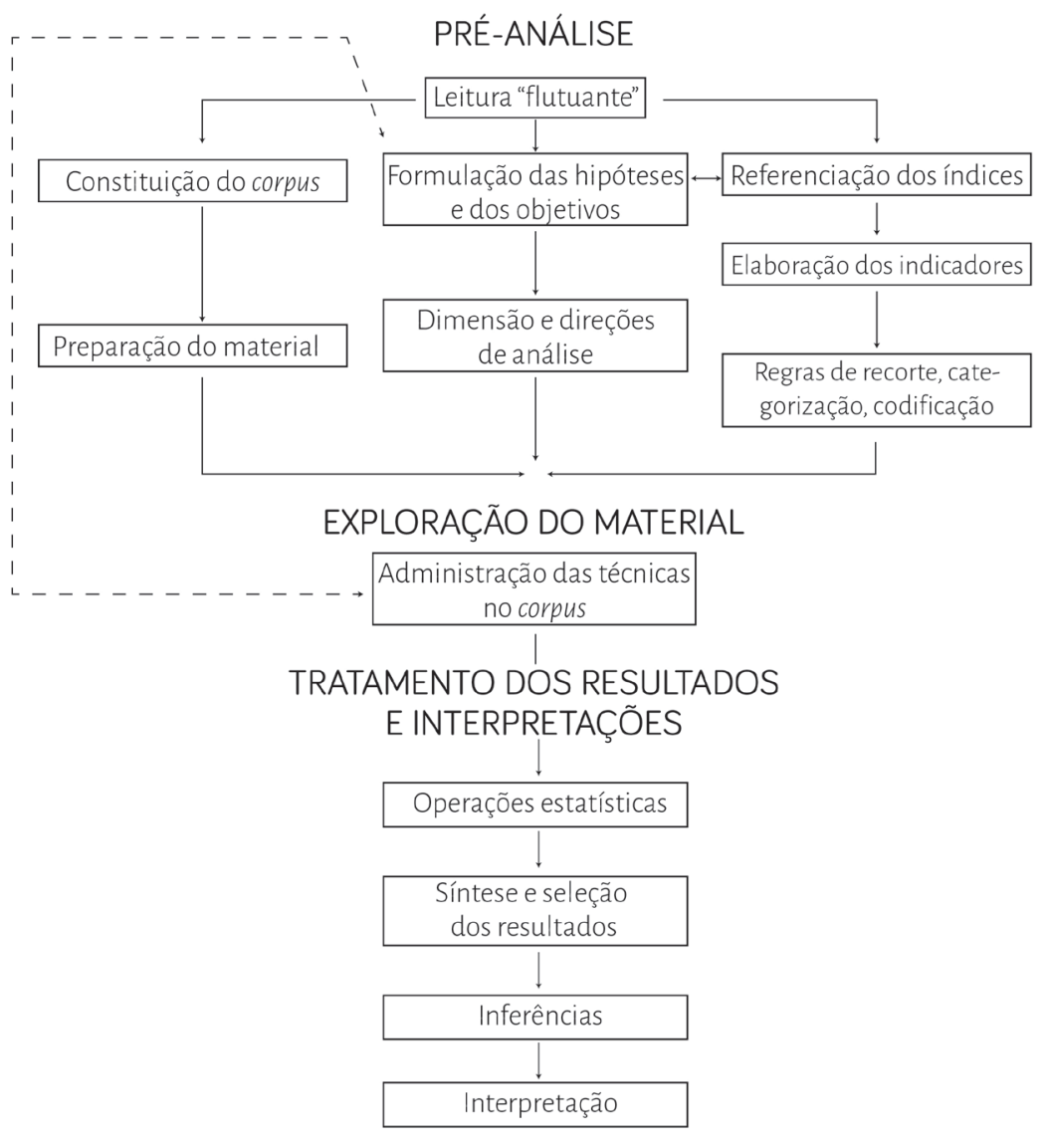


Ensino da Fotografia e as Tecnologias Digitais de Informação e Comunicação: um estudo com discentes de uma graduação de Design

\section{Resultados e discussões}

Foram consultados 36 estudantes de um curso de graduação em Design de uma Universidade Pública. Esse grupo estava dividido em três turmas, compostas por 14,13 e 9 alunos respectivamente.

Os grupos focais ocorreram, como mencionado anteriormente, em três dias: 10, 21 e 22 de agosto de 2018. 0 objetivo foi realizar a técnica no início do semestre para captar melhor as expectativas e percepções quanto à disciplina de fotografia antes dos estudantes tomarem conhecimento do conteúdo como um todo. Dessa forma, os grupos focais foram realizados na segunda aula do calendário da disciplina.

Os três encontros iniciaram-se da mesma forma. Primeiramente, com a explicação de como a entrevista seria conduzida; posteriormente, efetuou-se a entrega do termo de consentimento livre e esclarecido e do questionário, bem como explicitou-se que as discussões seriam registradas em áudio.

Após o preenchimento do termo, foram entregues o questionário

Fig 3 Faixa etária dos estudantes Fonte: Das autoras, 2019

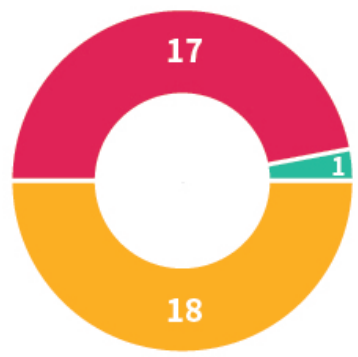

- Não domino - Domino em partes $=$ Domino completamente

Fig 4 Grau de familiaridade

com a fotografia

Fonte: Das autoras, 2019 para a caracterização do perfil dos estudantes. Findado o preenchimento dos instrumentos, deu-se início à discussão em grupo, que teve uma duração média de 30 minutos.

A maioria dos estudantes participantes consultados (19) está na faixa etária de 17 a 20 anos, 15 estão na faixa dos 21 a 29 e apenas 2 entre 30 e 39 , configurando um grupo relativamente jovem, como representado na figura 3.

Os alunos estão inseridos em diferentes semestres do curso de Design, sendo 26 inscritos no terceiro $\left(3^{\circ}\right)$ semestre, três no quarto $\left(4^{\circ}\right)$ semestre, dois no segundo $\left(2^{\circ}\right)$ e sexto $\left(6^{\circ}\right)$ e um aluno para cada um dos seguintes semestres: primeiro $\left(1^{\circ}\right)$, sétimo $\left(7^{\circ}\right)$ e oitavo $\left(8^{\circ}\right)$. Cabe ressaltar que, dentre os participantes, havia alunos especiais de outros cursos como Museologia, Ciências da Computação, Física e Oceanografia. Destaca-se que a disciplina de fotografia digital está alocada no terceiro semestre da matriz curricular do curso de Design consultado.

Quando convidados a avaliar o seu grau de familiaridade com a fotografia, 50\% (18) dos estudantes afirmam não dominar os princípios fotográficos, enquanto $47,2 \%$ (17) consideram dominar em partes e apenas $2,8 \%$ (1) declara dominar completamente, como pode ser visto na figura 4.

Quanto ao conhecimento ou utilização dos princípios da fotografia antes da disciplina de fotografia digital, 19 dos 36 estudantes afirmaram não conhecer nem utilizar tais princípios, 15 mencionaram utilizar apenas para fins de entretenimento e 2 declararam utilizar para trabalho e para entretenimento.

Quando questionados sobre a sua relação com a fotografia, a maioria dos alunos da turma 1 afirmaram utilizar o smartphone para fotografar diariamente, assim como grande parte desse grupo entende que muitos elementos da linguagem fotográfica eram utilizados de forma intuitiva antes do início da disciplina, visto que não conheciam a linguagem da fotografia. Desse grupo, apenas três alunos possuíam câmera fotográfica digital, mas afirmaram ter pouca familiaridade com as configurações do aparato. 
De modo geral, os alunos declararam ter expectativas altas quanto à disciplina e ao conhecimento que seria adquirido ao final do semestre. Além disso, 10 dos 14 alunos que compuseram a turma 1, mencionaram a ligação da fotografia com as atividades da área do Design, assim como a relação dos conhecimentos adquiridos nos primeiros semestres do curso de Design com a disciplina de fotografia digital.

Além disso, os alunos mencionaram buscar referências visuais e de estilo no trabalho de fotógrafos consagrados e contemporâneos, como afirma um participante:

o que eu uso mais como base para a fotografia em si, é seguir vários fotógrafos e olhar o que eles estão fazendo, como eles estão enquadrando uma pessoa, que forma eles estão fotografando (Participante Turma 1).

Todos os participantes afirmaram utilizar aplicativos para edição de imagens, mas nenhum conhecia aplicativos voltados ao ensino da fotografia. Durante a discussão, o grupo como um todo enfatizou em diferentes situações a necessidade de aprender, durante a disciplina, a operar as câmeras profissionais digitais e os equipamentos do estúdio.

Quando perguntados sobre como as tecnologias digitais poderiam contribuir na disciplina de fotografia, os alunos apontaram algumas questões, tais como: formas de auxiliar a disciplina por meio de plataformas digitais e aplicativos, menor dependência das câmeras profissionais e do conhecimento específico do professor. As declarações a seguir corroboram tais aspectos:

\footnotetext{
Acho que é importante facilitar o conhecimento com base no que a gente tem acesso e não precisar de uma câmera pra tirar uma foto e ter uma boa nota na disciplina (Participante Turma 1).
}

Ao perguntar aos alunos como deveria ser um material para apoiar o ensino da fotografia foram destacas sugestões como a integração de uma plataforma digital que possibilitasse o compartilhamento das imagens e troca de informações e também a utilização de referências de fotógrafos contemporâneos.

A maioria dos participantes da turma 2, quando questionados sobre a sua relação com a fotografia, afirmaram utilizar o smartphone para fotografar diariamente. Além disso, grande parte dos alunos acredita que aprender técnicas de edição de imagens e de manuseio de câmeras profissionais digitais é fundamental para a fotografia contemporânea. Desse grupo, quatro alunos possuíam câmeras fotográficas digitais, porém afirmaram ter pouca familiaridade com as configurações do aparato.

De modo geral, os alunos declararam ter poucas expectativas quanto à disciplina e ao conhecimento que seria adquirido ao final do semestre, visto que o grupo enfatizou que a prática com equipamentos profissionais é essencial e há uma defasagem de aparatos no curso em que estão inscritos. 
Apenas um participante afirma buscar referências no trabalho de fotógrafos consagrados e contemporâneos e cinco alunos mencionaram a necessidade de compreender a linguagem da fotografia aliada à prática:

Eu acho que o equipamento ajuda sim, mas não adianta ter um bom equipamento, sem ter a sensibilidade e conhecimento pra bater uma foto legal. Existem várias formas de você tirar a foto da mesma coisa e transmitir coisas diferentes (Participante Turma 2).

Assim como a turma 1, todos os participantes da turma 2 afirmaram utilizar aplicativos (Pixlr, Instagram e Prisma) e softwares (Adobe Photoshop) para edição de imagens, mas nenhum conhecia aplicativos voltados ao ensino da fotografia.

Quando questionados sobre como as tecnologias digitais poderiam contribuir na disciplina de fotografia, os alunos explicitaram dois eixos de possibilidades durante a discussão, sendo vídeos tutoriais para auxiliar nas explicações sobre as configurações das câmeras e uma plataforma digital para compartilhamento de imagens capturadas durante a disciplina.

Ao questionar os alunos da turma 3, sobre a sua relação com a fotografia, a maioria afirmou utilizar o smartphone para fotografar quando necessário. Dos participantes da turma 3, apenas dois possuíam câmera fotográfica digital, sendo que um aluno declarou trabalhar profissionalmente na área de fotografia e dominar a linguagem fotográfica e o outro afirmou ter pouca familiaridade com as configurações do aparato.

De modo geral, assim como a turma 1, os alunos declararam ter expectativas altas quanto à disciplina e ao conhecimento que seria adquirido ao final do semestre. Além disso, 4 dos 9 alunos que compuseram o grupo, mencionaram a ligação da fotografia com as atividades da área do Design, assim como a relação dos conhecimentos adquiridos nos primeiros semestres do curso de Design com a disciplina de fotografia digital.

Os alunos mencionaram, ainda, que há necessidade da teoria ser trabalhada em paralelo com as técnicas e a prática, como explicitam as declarações a seguir:

[...] sem conhecimento não adianta ter um baita equipamento que não vai tirar uma foto bonita (Participante Turma 3).

A gente estuda a história da fotografia, mas não sabe o que está sendo produzido agora. A fotografia contemporânea já tem uma outra perspectiva e abordar essa parte é muito importante (Participante Turma 3).

Assim como as turmas anteriores, todos os participantes da turma 3 afirmaram utilizar aplicativos e softwares para edição de imagens. Um participante citou a rede social Flickr por disponibilizar as configurações das ima- 
gens pertencentes ao seu banco de dados, visto que, segundo o estudante, facilita a análise e reprodução de fotografias para estudo. Contudo, novamente nenhum participante conhecia aplicativos voltados ao ensino da fotografia.

Quando questionados sobre como as tecnologias digitais poderiam contribuir na disciplina de fotografia os alunos afirmaram que um material dinâmico e interativo seria interessante e despertaria mais interesse do que apenas materiais impressos.

O quadro 1, a seguir, destaca as principais contribuições dos 36 alunos sobre como deveria ser, a partir das percepções deles, um material para apoiar o ensino da fotografia:

\begin{tabular}{ll}
\hline Turma & Contribuições \\
\hline \multirow{2}{*}{$\begin{array}{l}\text { Buscar aparatos que estão disponíveis a nós. Mudar um pouco a dinâmica de } \\
\text { aula para despertar a curiosidade e querermos aprender mais. }\end{array}$} \\
$\begin{array}{l}\text { Que possamos interagir com os colegas, porque às vezes tem um } \\
\text { trabalho muito legal e queremos saber como foi feito. Para podermos } \\
\text { trocar e compartilhar informações e não ficar somente no que sabemos }\end{array}$ \\
$\begin{array}{l}\text { Estar sempre atualizado, ao invés de usar as mesmas imagens bases pra } \\
\text { dar aula, quem sabe abrir o Instagram e olhar o que outras pessoas } \\
\text { estão fazendo. Também seria interessante o professor mostrar os } \\
\text { trabalhos de anos anteriores e explicar como foram feitos. }\end{array}$ \\
$\begin{array}{l}\text { Trazer um material que fosse diferente da apostila, que fosse interativo, } \\
\text { online para ser atualizado de forma constante. }\end{array}$ \\
$\begin{array}{l}\text { Vídeos para ser usados como um reforço, porque às vezes saímos para } \\
\text { fotografar e temos dúvidas, aí ao invés de chamar o professor, seria } \\
\text { possível consultar, na hora, pelo smartphone. }\end{array}$ \\
$\begin{array}{l}\text { Se fosse ter vídeos, teria que ser para ver em casa, e esses vídeos teriam } \\
\text { que ter menos de } 5 \text { minutos, porque vídeos muito longos não prendem } \\
\text { a atenção. }\end{array}$ \\
$\begin{array}{l}\text { Uma plataforma digital para distribuir as fotos da turma, compartilhar } \\
\text { as nossas fotos entre nós e podermos ajudar uns aos outros e fazer } \\
\text { análises das nossas imagens e dos colegas. }\end{array}$ \\
$\begin{array}{l}\text { Se for dinâmico acredito que seria mais interessante, se for algo no } \\
\text { estilo manual não vai chamar atenção e nem nos engajar. De modo } \\
\text { geral, seria melhor aceito se fosse no estilo de um aplicativo. }\end{array}$ \\
$\begin{array}{l}\text { Uma plataforma tipo o Flickr seria interessante, para compartilharmos } \\
\text { os nossos projetos com os colegas e podermos trocar ideias com eles } \\
\text { sobre como eles fotografam. }\end{array}$ \\
\hline
\end{tabular}

Quadro 1 Síntese das principais contribuições dos alunos Fonte: Das autoras, 2019

A maioria dos alunos afirmaram que a relação deles com a fotografia é basicamente construída pela utilização da câmera de seus smartphones para fotografar diariamente ou quando necessário, visto que é um aparato que está disponível com maior facilidade. Bem como, destaca-se do quadro anterior, os apontamentos quanto a considerar a possibilidade de análise colaborativa das produções de aula e o compartilhamento de informações técnicas e conceituais através de ferramentas presentes em uma plataforma digital. 


\section{Considerações finais}

A fotografia possui uma estreita relação com as atividades do Design e constitui-se primordial à produção cultural contemporânea. Nesse sentido, o ensino da fotografia requer processos de inovação constante para manter a sua relevância no contexto contemporâneo. Para tanto, esta pesquisa, buscou identificar as expectativas dos alunos de um curso de Design quanto à disciplina de fotografia e quanto ao conhecimento prévio sobre tecnologias digitais que apresentam potencial para apoiar o ensino dessa disciplina.

Assim, o grupo de estudantes consultado pode ser considerado relativamente jovem, visto que a maioria é composta por estudantes que estão na faixa dos 17 a 20 anos. De acordo com uma pesquisa realizada pela Think with Google (GOOGLE, 2017) sobre a Geração Z, esses jovens cresceram junto com a tecnologia digital, se conectam e compartilham suas experiências prioritariamente pelos seus smartphones, visto que, segundo as estatísticas da pesquisa, os dispositivos mais utilizados são smartphones (78\%), notebook (69\%), televisão (68\%) e videogames (62\%).

Nota-se que a maioria do grupo de discentes está matriculada no terceiro semestre do curso ou em semestres avançados, contudo, metade dos participantes afirmam não ter contato com a linguagem da fotografia. Além disso, poucos alunos percebem a relação dos conhecimentos adquiridos nos primeiros semestres do curso de Design com a disciplina de fotografia digital.

Também foi possível perceber algumas aproximações e diferenças entre os grupos. Dessa maneira, a maioria dos alunos afirmaram que a relação deles com a fotografia é basicamente construída pela utilização da câmera de seus smartphones para fotografar diariamente ou quando necessário. As turmas 1 e 3 declararam ter expectativas altas quanto à disciplina e ao conhecimento que seria adquirido ao final do semestre, enquanto a turma 2 afirmou ter poucas expectativas. Infere-se que essa diferença nas expectativas seja devido à ênfase que o grupo 2 deu apenas à prática com aparatos profissionais, visto que os participantes dos demais grupos mencionam a necessidade de se compreender a teoria aliada às técnicas e à aplicação prática.

Contudo, houve convergências entre as discussões dos grupos. Ao questioná-los sobre como as tecnologias digitais poderiam auxiliar no ensino da fotografia, por meio de suas falas, destacadas no quadro 1 apresentado anteriormente, percebeu-se a necessidade de aulas mais dinâmicas e colaborativas. Nesse sentido, os três grupos mencionaram que gostariam de compartilhar e trocar informações com os colegas sobre as atividades da disciplina e sobre fotografia de uma maneira geral, em um ambiente digital que não dependesse somente dos encontros presenciais.

Dessa maneira, ao buscar uma visão centrada no estudante, este estudo abre caminho para a pesquisa e proposição de novas estratégias para o ensino da fotografia no âmbito acadêmico. E para continuidade deste estudo, considera-se a realização de novos grupos focais em outras instituições de ensino, visto que estudantes de diferentes contextos possuem pontos de vistas diferentes sobre os processos de ensino. 
1 A ubiquidade é definida como a capacidade de estar ao mesmo tempo em toda parte, o que lhe confere também o caráter de onipresença (AGUIAR; ALENCAR, 2014).

2 São relógios inteligentes que possuem funções semelhantes aos smartphones (TECHTUDO, 2018).

3 Referência aos óculos Spectacles, que capturam imagens e fazem filmagens. Foi desenvolvido pela mesma empresa dona do aplicativo de compartilhamento de imagens Snapchat (SPECTACLES, 2018).

4 Informações disponíveis no seguinte link: https://instagram-press. com/. Acesso em: 21 jan. 2019.

5 De acordo com Rodrigues (2014), entende-se alfabetização como o aprendizado das bases de uma linguagem e letramento como o aprendizado das práticas sociais simbólicas, as quais são utilizadas a partir do uso fluente da língua.

\section{Referências}

ABRAHMOV, Shlomo. L.; RONEN, Miky. Double blending: online theory with on campus practice in photography instruction. In: Innovations in Education and Teaching International, v. 45, n. 1, p. 3-14, 2008.

AGUIAR, Rafael B.; ALENCAR, Marlyvan M. Interfaces ubíquas sob a perspectiva do Design de Interação. Iniciação: - Revista de Iniciação Científica, Tecnológica e Artística, São Paulo, v. 4, n. 3, p.1-10, out. 2014. Disponível em: http://www1.sp.senac.br/hotsites/blogs/revistainiciacao/wp-content/uploads/2014/11/68_IC_artigo.pdf. Acesso em: 31 maio 2019.

AMARAL, Ana Leticia Oliveira do; GONÇALVES, Berenice Santos; GITIRANA, Marcelo; Ensino da fotografia no âmbito da educação superior em Design: uma revisão sistemática de literatura, p. 1061-1074. In: Anais do 13ํㅡㄹ Congresso Pesquisa e Desenvolvimento em Design (2018). São Paulo: Blucher, 2019.

BARDIN, Laurence. Análise do conteúdo. São Paulo: Edições 70, 2016.

FAKRI, Siti. H. M.; YUSOFF, Amri,; SAID, Che. S. Applying gestalt variables in learning photography with virtual games. Jurnal Teknologi, Johor Bahru, Malásia, v. 75, n. 3, p.111-115, 2015. GOOGLE. It's Lit: a guide to what teens think is cool. Austin, 2017.

HAND, Martin. Ubiquitous photography. Cambridge: Polity Press, 2012. 200 p.

MANOVICH, Lev. Image future. animation, v. 1, n. 1, p. 25-44, 2006.

MANOVICH, Lev. Instagram and Contemporary Image. [S.L.]: [s.n.], 2017. 148 p. Disponível em: http://manovich.net/content/04-projects/144-instagram-and-contemporary-image/ instagram_book_manovich.pdf. Acesso em: 29 jun. 2019.

MARTIN, Bella; HANINGTON, Bruce. Universal methods of Design. Beverly: Rockport Publishers, 2012.

MARTÍN-BARBERO, Jesus. A Comunicação na Educação. São Paulo: Ed. Contexto, 2014. 
MARZAL, Javier.; SOLER, María. Consumption Patterns and Uses of Photography in Digital Era among Communication Students. Comunicar, v. 19, n. 37, p. 109-116, 2011.

NIEBERDING, William J. Photography, phenomenology and sight: Toward an understanding of photography through the discourse of vision. 2011. Tese de Doutorado. The Ohio State University.

RIVERA, Carlos Delgado. Enseñanza de la fotografía en ambientes virtuales de aprendizaje. In: Undecima Conferencia Iberoamericana en Sistemas, Cibernetica e Informatica, Noveno Simposium Iberoamericano en Educacion, Cibernetica e Informatica, SIECI 2012, p. 289-293. Disponível em: http://www.ventanagrafica.co/datos/CursoFoto.pdf. Acesso em: 27 jun. 2019.

ROBBIE, Diane.; ZEENG, Lynette. IT's evolving, they're changing, we're listening: everybody's learning. In: ASCILITE 2008 - The Australasian Society for Computers in Learning in Tertiary Education, p. 809-818, Anais... 2008.

ROBBINS, J. Photographic education in the digital age. RPS Journal, v. 140, n. 5, p. 239-41, 2000. RODRIGUES, Walace. Letramento imagético e midiático em arte-educação. Conhecimento e Diversidade, Niterói, v. 6, n. 12, p.90-101, 2014. Disponível em: http://www.revistas.unilasalle.edu. br/index.php/conhecimento_diversidade/article/view/1607/1295. Acesso em: 08 abr. 2019.

ROGERS, Yvonne; SHARP, Helen; PREECE, Jennifer. Design de interação: além da interação humano-computador. Bookman, 2013.

RUBINSTEIN, Daniel. Towards Photographic Education. Photographies, [s.l.], v. 2, n. 2, p.135-142, 8 set. 2009. Disponível em: < https://www.academia.edu/528410/Towards_Photographic_Education>. Acesso em: 10 abril 2019.

SANTAELLA, Lúcia. Linguagens líquidas na era da mobilidade. São Paulo: Paulus, 2014. SEMESP, Sindicato das Mantenedoras de Ensino Superior (Ed.). Diretrizes de Política Pública para o Ensino Superior Brasileiro 2017. São Paulo, 2017. Disponível em: http://www.semesp. org.br/wp-content/uploads/2017/09/Diretrizes-de-Política-08-08-.pdf. Acesso em: 3 fev. 2019. SILVA, Andressa Hennig; FOSSÁ, Maria Ivete Trevisan. Análise de conteúdo: exemplo de aplicação da técnica para análise de dados qualitativos. Qualitas Revista Eletrônica, Campina Grande, v. 17, n. 1, p.1-14, jan. 2015. Disponível em: http://revista.uepb.edu.br/index.php/ qualitas/article/view/2113/1403. Acesso em: 16 abr. 2019.

SILVA, Wagner Souza e. Foto 0 | Foto 1. São Paulo: Fapesp, 2016. 200 p.

SOBRAL, João E. C. A linguagem fotográfica na formação do designer em um ambiente de convergência tecnológica. 2011. 145 f. Tese (Doutorado) - Curso de Pós-graduação em Design, Departamento de Artes e Design do Centro de Teologia e Ciências Humanas, Pontifícia Universidade Católica do Rio de Janeiro - Puc-rio, Rio de Janeiro, 2011. Disponível em: https://www.maxwell.vrac.puc-rio.br/Busca_etds.php?strSecao=resultado\&nrSeq=21687@1. Acesso em: 24 jun. 2019.

TORI, Romero. Educação sem distância: as tecnologias interativas na redução de distâncias em ensino e aprendizagem. São Paulo: Senac São Paulo, 2010. 254 p.

WAUTERS, Ricardo. La enseñanza de la fotografía en tiempos de cambio. In: Reflexión Académica En Diseño y Comunicación. Buenos Aires, v. 21, p.71-73, ago. 2013. Disponível em: http://fido.palermo.edu/servicios_dyc/publicacionesdc/archivos/430_libro.pdf.

ZHANG, Yuhong.; HAO, Xiaofang.; WANG, Jing.; JIAO, Weiting.; DAI, Wei. The Thinking of Inte-

Recebido: 11 de agosto de 2019 . Aprovado: 07 de fevereiro de 2020. grating between Informational Technology and Photography Course. In: International Journal of Digital Content Technology and its Applications, v. 7, n. 2, p. 487-494, 2013. 